\title{
Assessment of Calibration on Clinical and Practical Supervision among Dental Lecturers.
}

\author{
Zurainie Abllah ${ }^{1}$, Munirah Yaacob ${ }^{2}$ \\ 'Department of Paediatric \& Dental Public Health, Kulliyyah of Dentistry, International Islamic University \\ Malaysia (IIUM) Kuantan \\ ${ }^{2}$ Department of Restorative Dentistry, Kulliyyah of Dentistry, IIUM Kuantan
}

\begin{abstract}
:
Aim:The purpose of this assessment was to examine the variation among faculty members of Kulliyyah of Dentistry in supervising the clinical work of students. Introduction:Consistency in the evaluation of clinical decision-making is necessary for reliable assessment of student performance and effectiveness of clinical teaching. However little has been done to examine variation in dental clinical supervision. As a professional dental practitioner and lecturer, I feel this exercise is crucial as to give the best and 'adil (justice) to students when doing assessment of work. Materials \& Methods :Twenty clinical lecturers from Kulliyyah of Dentistry were given a set of criteria of rubric, and undergone twelve stations of clinical models focusing on several procedures in dentistry clinical works. The rubric and clinical models were prepared in six different groups of specialty: Periodontic, Conservative, General Dental Practitioner, Oral Surgery, Endodontic and Prosthodontic Dentistry. Lecturers go for baseline calibration and received training by 6 content experts immediately. Re-calibration was done after training. The time given for each station is 5 minutes. The rubrics consist of 57 points. The examination used dental mirror, dental probe, dental models, $x$-rays, copies of students' case note and manikin. Kappa statistics were used to determine inter-examiner reliability at baseline and re-calibration. Results : For inter-examiner statistic, the baseline calibration on 20 clinical lecturers indicated an inter-rater kappa ranging from 0.05-0.5. Re-calibration on the same 20 packages after training indicated an inter-rater kappa of 0.11-0.42. Activity kappa was in the slight to moderate agreement. Performance of majority of examiners improved with time. Conclusion:The calibration of clinical lecturers should be performed regularly as it is crucial to maintain the uniformity of the examiners reliability. Furthermore the training needs to be conducted in an effective environment to improve performance. It is hoped that continuous training nurturing the "righteous individuals" which is one of the goals in Shariah principle.
\end{abstract}

KEYWORDS: calibration, assessment, dental lecturers

\section{INTRODUCTION}

A major portion of dental education involves close supervision of students during their acquisition of psychomotor and clinical decision making skills in a simulated environment and in the clinical setting. Calibration and standardization of the performance of supervisors are crucial for effective teaching and learning. Many studies have reported that calibrating the performance of clinical faculty members can promote consistent clinical lessons and reduced the effects of lessons variations in educational atmospheres ${ }^{3,5}$.

Calibration training should use a standard rubric to evaluate students and the ability to repeat those values in altered conditions ${ }^{3,4}$. Well-defined criteria that are easily comprehensible to students will enhance development of decision making skills and

Corresponding author:

Zurainie Abllah

Department of Paediatric \& Dental Public Health, Kulliyyah of Dentistry,

International Islamic University Malaysia,

Jalan Sultan Ahmad Shah, 25200 Kuantan, Pahang

Email: drzura@iium.edu.my also assist in calibrating of teaching staff. In addition, post calibration training that involves accurate conditions and settings similar to practice delivers the most real outcomes ${ }^{4}$.

Variation in decision-making by supervisors will contribute to variation in student performance and high error rate in decision making. North American dental students identified inconsistent clinical feedback as one of the major obstacles in achieving clinical competence ${ }^{2}$. There are studies that have demonstrated inconsistencies in clinical decision when interpreting examinations and treatment planning of periodontal disease between two members of faculty and a student ${ }^{6,7}$. The credibility of instructors can be conceded when instructor assessments vary with clinical presentation of similar students or similar case assessment ${ }^{8,9}$. Consequently students may be deterred from learning.

Hence, this study was conducted to determine the variation among faculty members in supervising clinical work of students'. 


\section{MATERIALS \& METHODS}

We invited all clinical lecturers in Kulliyyah of Dentistry (KOD) International Islamic University of Malaysia (IIUM) and it is a Kulliyyah event to undergo a calibration workshop that is understood by all of them about the purpose. The workshop training is the first to be conducted in Kulliyyah of Dentistry, which involved all clinical lecturers. The participation in the workshop is based on mutual agreement that the findings will be beneficial to the Kulliyyah as a whole. However the participant were permitted to withdraw from the workshop at any time of and it won't affect their annual increment or mark performance for the year by the Kulliyyah authorities.

Several content experts prepared the rubric that was to be used in the workshop. The content experts were selected based on their specialty and department in KOD. They are from the following departments: Periodontic, Conservative, Endodontic, General Dental Practice (GDP), Oral Surgery (OS) and Prosthetic. The rubric was outlined and was discussed 6 times before being finalized.

The station set by the Periodontic department was on calculus detection. The lecturers/participants needed to do calculus inspection, assess calculus removal and the smoothness of the surface of teeth. Tooth 'frasaco' model with artificial calculus was used in this station. For the conservative department, 3 stations were allocated as below. The first station, the content experts wished the participants to inspect the amalgam Class II cavity preparation. Here the participants needed to check on occlusal outline form, pulpal floor, proximal outline form and proximal internal form. The second station is to assess the liner placement. Here the participants were instructed to check on the placement of the liners and assess the excess of liners on the pulpal floor. The third station is on rubber dam isolation. The tooth 'frasaco' model and manikin was used in these 3 stations. The GDP department has given 2 stations for the participants to assess. The first station is on examination and investigation. The second station was on diagnosis and treatment plan. The station used student's case note that was taken from their previous work. All the confidential information was blackened and not exposed to the participants. The participants were required to assess the student's record whether they performed the necessary examination and investigation and whether they performed proper diagnosis and treatment plan for the patients. Endodontic department had the next 2 stations. The first station was to access cavity for root canal treatment. This station used the extracted teeth and 2 models. Model A was done poorly and Model B was done in good way. The second station is about the quality of root filling where 2 x-rays of guttapercha condensed in root canal of extracted teeth. Next was the station allocated for OS department where the focus was on writing of 'drug prescriptions'. The last was the Prosthetic department. The first station by the department was on final impression. The material used was the picture of the impression that was taken previously. The second station was about the teeth setting where a model of a set of teeth was used and mounted on articulator.

In the calibration session, the participants used a set of the evaluation criteria. It is called GAIR evaluation criteria ( $G$ is for good achievement as set by certain criteria, $A$ is acceptable achievement with minor error, I is for improvement of work required to reach acceptable level and $R$ is for redo required- work is not accepted and it should be repeated). The total number of stations was 10 . The points to be answered are 57 points of criteria. The answer of all the points should be chosen from GAIR.

The participants go through the first exercise using the first booklet (pink colour). Immediately after that, the participants received training and feedback from the 6 content experts. Then, the participants go through again another cycle of exercise with the same cases of 11 stations and this time, books were blue.

The participants in the exercise were 34 . However only 20 of them were valid cases to be used in the analysis, as the other remains 14 are not valid as for some reasons, such as dropped out, and the answer was not following the exact criteria.

The time allocated to go through the questions and answer each question was roughly around five minutes based on approximations of oral reaction times during previous preparation sessions. A total of 55 minutes was needed to complete all the stations with all the eleven cases.

The exercise using Kappa agreement where the Gold Standard answer received from all content experts of following departments: periodontic, conservative, endodontic, GDP, OS and prosthetic to assess the response and answer.

\section{RESULTS}

A total of 34 lecturers/participants from KOD, IIUM participated in the exercise. However, only 20 participants were included in the analysis as the other 14 participants failed to comply with the instructions and 2 of the participants dropped out. As for the years of experience in dental field is shown in Table 1. The participants experience in dental field can be categorized into 3 groups.

Table 1: Years of Experience

\begin{tabular}{cc}
\hline Years of experience & No. of participants $(\mathrm{N}=20)$ \\
\hline $1-4$ years & 1 \\
$5-10$ years & 5 \\
$>10$ years & 14 \\
\hline
\end{tabular}


As shown in table 2, the most participants for the exercise came from Prosthodontics, Oral Surgery (OS), Dental Public Health (DPH) and. On hindsight, the Orthodontic and Outpatient department had the least participation, as the number of people in the department was also least.

Table 2: Number of participants according to department

\begin{tabular}{ll}
\hline Department & \multicolumn{2}{l}{$\begin{array}{l}\text { No. of participants } \\
(\mathrm{N}=20)\end{array}$} \\
\hline General dental practice & 2 \\
Prosthodontic & 4 \\
Oral surgery & 4 \\
Dental public health & 4 \\
Paediatric & 4 \\
Orthodontic & 1 \\
Outpatient & 1 \\
\hline
\end{tabular}

Table 3: Kappa value range according to department

\begin{tabular}{lll}
\hline Department & $\begin{array}{l}\text { Kappa value } \\
\text { pre } \\
\text { interventio } \\
\mathrm{n} \text { (range) }\end{array}$ & $\begin{array}{l}\text { Kappa value } \\
\text { post } \\
\text { intervention } \\
\text { (range) }\end{array}$ \\
\hline $\begin{array}{l}\text { General dental } \\
\text { practice }\end{array}$ & $0.19-0.25$ & $0.26-0.27$ \\
Prosthodontic & $0.24-0.50$ & $0.24-0.39$ \\
Oral surgery & $0.05-0.39$ & $0.11-0.33$ \\
Dental public health & $0.25-0.41$ & $0.24-0.41$ \\
Paediatric & $0.23-0.29$ & $0.35-0.42$ \\
Orthodontic & 0.17 & 0.35 \\
Outpatient & 0.28 & 0.23 \\
\hline
\end{tabular}

The kappa value ranged from slight to moderate agreement. It also showed that most of the department improved after being given training. However, there were also lecturers who showed a reduced score after being given training.

\section{DISCUSSION}

No earlier studies have studied the calibration of clinical and practical supervision between lecturers in the Kulliyyah of Dentistry (KOD). All the lecturers/participants in the study have had at least a basic degree of Dental surgeons and used the same classification structure. Thus it was anticipated that there would be a degree of agreement between them and the Gold Standard ${ }^{13}$. Among all the stations that were set up, it is thought that the part on diagnosis was the most important one to be calibrated, as it is intended to be a summary statement that represents a summative analysis of all the information. While Armitage and Cullinan ${ }^{1}$ suggested that specialists ought not to argue about a diagnosis if the suggested treatment will be the same nevertheless how the condition is shown. There are few sensible explanations why practitioners should agree on coming to an agreement of a diagnosis. The diagnosis is very important as it serves as the basis for the most suitable treatment plan for the patient. Diagnosis also offers a good communication between clinicians, and delivering information to the patients $^{10,11}$.

Among the essential skills that clinicians need to improve is to learn how to interpret clinical data, to formulate a diagnosis and treatment plan during their training years. If there are inconsistency among specialist who taught the students, it will results in misperception among the students and will jeopardized their clinical skills too ${ }^{12}$. The results from inconsistency of the justification will be as severe as inappropriate treatment. The role as a specialist who taught the students is very important as they are the one who guide the students through a clinical exams and other assessment. Calibration is very important to show that an agreement has been achieved among the specialist and therefore the same understanding when come to deliver the knowledge to the students. In John et al. $^{2}$, responses for diagnoses and treatment planning for periodontal cases were compared between dental students and faculty members. This study found agreement to be relatively low $(0.35-0.54)$, which is very similar to what we found.

The gold standard was set by the content expert from each departments and it is used as a standard measurement in order to have a balanced and standard supervision given to the students in the clinical setting. It is very important to have the gold standard so that we could identify which candidate achieved closest to or least similar to the Gold standard.

As in Table 3, there were overall low Kappa score of similarity across the departments and it was shown that there are wide variations of grade or mark given by the lecturers to the students. This can indicate that the agreements were low and show variations between subject and gold standard. The Kappa provides for the inclusion of ratio-scaled degrees of disagreement (or agreement) to each of the cells of the kappa table of joint nominal scale assignments such that disagreements of varying gravity (or agreements of varying degree) are weighted accordingly?

Islam has given a lot of importance to education and has declared it compulsory for every Muslim to acquire knowledge. Prophet Muhammad (PBUH) has said "It is compulsory for every Muslim men and women to acquire knowledge."

This shows the importance of knowledge in Islam. As 
IMJM Volume 17 Special Issue No 2

such what would be the status of a teacher in Islam? Well, here are few quotes that would throw light on the standing of a teacher in Islam Prophet (PBUH) said, "I am sent as a teacher."

This shows that a teacher plays an important part in raising a well-groomed 'ummah'. Most important is that the teacher is transferring knowledge the correct and good way, and for the students to receive knowledge from him/her. As in dentistry, the knowledge that is received from the lecturers will be used in treating patients. This is why standardization of assessment among lecturers is very important so that the lecturers convey the similar thought and knowledge so that students received the same information and skill from teachers. The other important part is calibration will avoid confusion among students. Lecturers in an institution received basic degree from different schools of thought and surely bring some differences in knowledge and practical of the techniques. This includes the years of graduates in practice that add to the differences.

In the Holy Quran, Allah (SWT) has mentions in Chapter 55 (Surah Ar-Rahman), Verse 7 " And the heaven, He raised it high, and He made the balance." This shows that need of having balance in our life and our duty as a professional. In Islam, this world is working in its own standard, and so does our daily work. Without standardization, the optimum result of the work will be jeopardized. We feel that this is very important workshop as it is to standardise the quality of supervision and grade that been given to the students so that at the end, the students who graduate from IIUM are all balanced and achieve the same standard when work in the field later.

In another surah in the Holy Quran, Allah (SWT) has mentions in Surah Al Mulk, Verse 3 "Who created the seven heavens one above another; you see no incongruity in the creation of the Beneficient Allah; then look again, can you see any disorder?" This shows that if the system has no standard, there would be incongruity. As in the application in the daily work as dental supervisor teaching students, if the dental lecturers and supervisors are not standardized, there will be incongruity of the various dental students' clinical works. The end result of this problem will be seen in patients whom they treat. Patient will suffer in case wrong decision or treatment had been given.

\section{CONCLUSION}

The calibration of dental clinical lecturers should be performed regularly as it is crucial to maintain the stability of the examiners reliability. Furthermore the training needs to be conducted in effective environment to achieve good results. It is hoped that the continuous training nurturing of "righteous individuals" which is one of the goals in the Shariah.

\section{ACKNOWLEDGEMENT}

I would like to acknowledge the IIUM for the opportunity to use the allocation provided by the RIGS grant, the number of grant is RIGS 15-0530053.

\section{REFERENCES}

1. Armitage GC. Diagnosis of periodontal diseases. Journal of Peri-odontology 2003;4(8):1237-47

2. Henzi D, Davis E, Jasinevicius R, et al. North American dental students' perspectives about their clinical education. Journal of Dent Educ 2006;70(4):361-77.

3. Haj-Ali R, Feil P. Rater reliability: short- and long-term effects of calibration training. Journal of Dent Educ 2006;70(4): 428-33

4. Christie C, Bowen D, Paarmann C. Effectiveness of faculty training to enhance clinical evaluation of student competence in ethical reasoning and professionalism. Journal of Dent Educ 2007;71 (8):1048-57.

5. Courts F. Standardization and calibration in the evaluation of clinical performance. Journal of Dent Educ 1997;61(12):947-9.

6. Drucker SD, Prieto LE, Kao DW. Periodontal probing calibration in an academic setting. Journal of Dent Educ 2012;76(11):1466-73.

7. John V, Lee SJ, Prakasam S, et al. Consensus training: an effective tool to minimize variations in periodontal diag- nosis and treatment planning among faculty and students. Journal of Dent Educ 2012;77(8):1022-32.

8. Lanning SK, Pelok SD, Williams BC, et al. Variation in periodontal diagnosis and treatment planning among clinical instructors. Journal of Dent Educ 2005;69(3):325-37.

9. Wallace JS, Infante TD. Outcomes assessment of dental hygiene clinical teaching workshops. Journal of Dent Educ 2008;72(10):1169

10. Weighted kappa: nominal scale agreement with provision for scaled disagreement or partial credit. Psychological bulletin 1968; 70(4): 213220

11. Park RD, Susarla SM, Howell TH, et al. Differences in clinical grading associated with instructor status. Eur Journal of Dent Educ 2009;13(1):31-8.

12. John V, Lee SJ, Prakasam S, et al. Consensus training: an effective tool to minimize variations in periodontal diagnosis and treatment planning among dental faculty and students. Journal of Dent Educ 2013;77(8):1022-32.

13. Lanning SK, Pelok SD, Williams BC, et al. Variation in periodontal diagnosis and treatment planning among clinical instructors. Journal of Dent Educ 2005;69(3):325-37. 
